\title{
MATHEMATICAL MODELLING OF DIGESTER-SCREW PRESS PROCESS FOR EXPRESSION OF OIL FROM OIL PALM FRUIT
}

\author{
${ }^{1}$ Badmus, G. A.; ${ }^{2}$ Owolarafe, O. K.; ${ }^{3}$ Osunleke, A.S.; ${ }^{4}$ Ajadi, S. O. and ${ }^{2}$ Ajayi, O. A. \\ ${ }^{1}$ Agricultural Engineering Research Division, The Nigerian Institute for Oil Palm Research, Benin City, Nigeria \\ ${ }^{2}$ Department of Agricultural and Environmental Engineering, Obafemi Awolowo University, Ile-Ife, Nigeria \\ ${ }^{3}$ Department of Chemical Engineering, Obafemi Awolowo University, Ile-Ife, Nigeria \\ ${ }^{4}$ Department of Mathematics, Obafemi Awolowo University, Ile-Ife, Nigeria \\ Corresponding Author's Email: owolarafe@yahoo.com \\ (Received: 20th August, 2019; Accepted: 20th September, 2019)
}

\section{ABSTRACT}

\begin{abstract}
In this study, mathematical models of flow of the sterilized oil palm fruit stream was developed for isothermal operations and solved analytically or in closed forms. Non-isothermal condition was not considered due to insignificant temperature differences of the fruit stream measured between the inlet and outlet of the digester screw press implying that the isothermal operation is applicable. The mathematical model developed was validated by comparing experimentally determined values of volumetric flow rate with that of the predicted value. Predicted values of volumetric flow rate obtained from the model simulations compared favourably well with the experimentally measured values obtained within the realistic operating conditions of the machine.
\end{abstract}

Keywords: digester- screw press, palm-oil, expression, models, volumetric flow, efficiency

\section{INTRODUCTION}

Processing of oil palm fruit into palm oil yields a lot of by-products including palm kernel, palm kernel cake and palm bunch which have numerous domestic and industrial applications. Palm oil, the principal product of the crop has a great number of uses. About 80 per cent of production is destined for human consumption with the balance going to animal feed and to various industries. Palm oil serves as the main cooking oil in Nigeria. In common with all fats, palm oil is a good source of energy and in addition the crude oil provides carotenoids (pro-Vitamin A) and tocopherol or Vitamin E (Babatunde, 1987).

Nigeria remains a distant fifth largest producer with less than 1 million tons of palm oil in 2009 behind Indonesia, Malaysia and Thailand in the world palm oil trade. Although Nigeria is now a net importer of palm oil, the total gross value of the production at current domestic prices is in the region of N120-150 billion annually which is very significant in terms of the Agricultural Gross Domestic Product of Nigeria (Omoti 2011). The Nigerian poor story has been adduced to lack of appropriate technologies for small and medium scale processors who occupy about $90 \%$ in the country oil palm sector (Owolarafe 2015). As a result, the development of appropriate technologies for the small and medium scale processors has been the worry of many research institutes in Nigeria.

Palm fruit processing generally involves five basic operations, which are fruit loosening, fruit sterilisation, digestion, oil extraction and clarification. At the level of the small scale processors, different versions of machine for each of the unit operations exist in Nigeria. Nearly all the unit operations have been mechanised but the extraction efficiencies seldom exceed $70 \%$ (Owolarafe and Oni 2011; Owolarafe 2015). Apart from this the capacity of the plants is low (about 1.5 tons/ hr of fresh fruit bunches). The Nigerian Institute for Oil palm Research (NIFOR) identified that the use separate machines for each of the unit operations involved accounts for low throughput and hence developed a machine (i.e digester -screw press) which combines digestion and expression operations (Badmus 1991). The initial throughput and extraction efficiency of the machine were 3 tons $/ \mathrm{hr}$ and $87 \%$, respectively. Oil loss of $13 \%$ is considerable and as result the machine has been undergoing modifications. It therefore becomes imperative to improve the design of the machine. Modelling of machines' operation has been found to be useful in improving the efficiency of such machines. Owolarafe et al. (2008) developed a model for 
improving extraction efficiency of hydraulic press (for palm oil). Similarly Jain and Jain (2015) developed a model for screw expulsion of oil from mustard and sunflower seeds. The results of the studies have been found useful in modifying the design of the presses. This current study undertook modelling of digester screw press with a few to identifying optimum specifications for machine parameters and working conditions that are consistent with high yield of oil extraction efficiency.

\section{MATERIALS AND METHODS Theoretical Consideration}

The theory of modelling flow of sterilized oil palm fruit stream through the improved digester screw press integration, oil palm fruit transfer and spring choke mechanism involves development of mathematical simulation of the sterilized oil palm fruit stream in partial differential and continuity equations of the transport and energy phenomena involving isothermal and nonisothermal operation conditions. Overall models of the flow and thereafter flow model in each of the three stages of the digester screw press (DSP) operation for the extraction of palm oil including the digestion by the stirring arms, transfer by the transfer arms and pressing by the single worm screw-in-perforated-cage as applicable to intermediate values of the arms and screw channel aspect ratio are presented. The isothermal operation of the improved DSP which assume no change in temperature and the non-isothermal situation indicating system internal heat generation were considered.

Figure 1 shows the schematic diagram of the digester- screw press with balloon reference (Badmus 2017). The horizontal digester shaft assembly is fitted with paddles called stirring arms in the digester section but the paddles in the transfer section are called transfer arms. The arms form a disjointed helical screw. The press shaft has a continuous flight screw called worm. For the sake of simplicity only continuous flights are assumed in the development of the present model.

The model development was based on the following assumptions:

i. the maceration of sterilized oil palm fruit was completed in the digestion section. Also the air contained in the sterilized oil palm fruit stream was forced out through the hopper leaving a homogeneous mixture of crude palm oil with nut fibre matrix in the digestion section to flow in to the transfer section. No pressure would develop at the feed section

ii. the transfer of the homogeneous digested oil palm fruit (pulp) stream was completed in the oil palm fruit transfer mechanism in to the cage of the screw press and the transfer operation is transient.

iii. the flow development started at the digestion section due to the action of the stirring arms, hence crude palm oil expression began in the digestion section (Owolarafe and Faborode, 2008) and it continues in the transfer section on to the pressing section.

iv. the temperature of the sterilized oil palm fruit stream remained constant in the digester screw press (Owolarafe et al. 2008). Actually the temperature would increase due to shearing action of the arms and worm screw shaft (mechanical dissipation) but the steel material of the digester pipe and screw press cage being a good conductor of heat and 


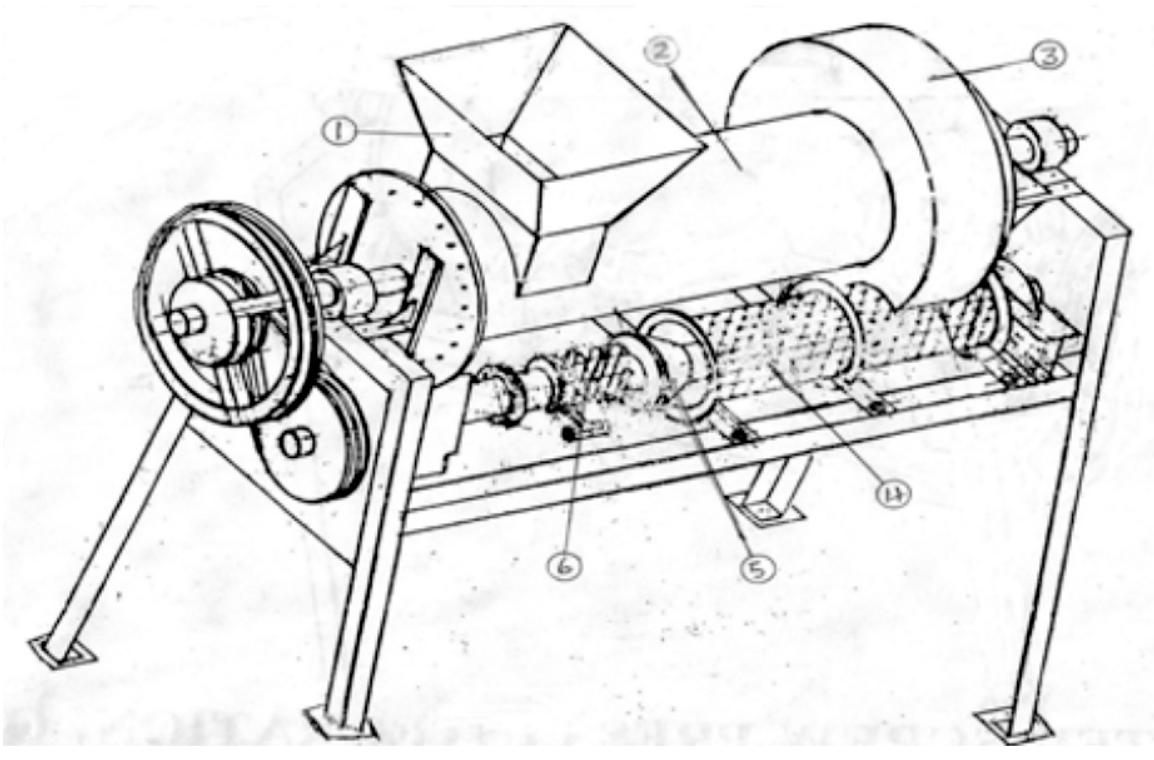

1-Hopper 2-Digester pipe 3-Transfer pipe 4-Perfurated cage 5-Conical choke 6-Spring

Fig. 1: Schematic diagram of digester screw press integration, oil palm fruit transfer and spring choke mechanism

v. cooler ambient would act as a temperature moderator. The temperature difference is negligible and hence, the flow is assumed to beisothermal.

vi. steady state of sterilized oil palm fruit stream flow is attained in the digester screw press; machine parameters do not change.

vii. leakage of crude palm oil occur at the pressing section through the holes perforated on the cage of screw press while the nut fibre residue (press cake) extrude from the end of pressing section.

The continuous helical flight on the shafts of the digester screw press is shown in Fig .2 and the sterilized oil palm fruit stream flow through a section of the digester screw press channel, that is, the space between the shaft surface and the pipe or cage wall and the stream element flow through the circular geometries in the $x, y, z$ coordinate system as shown in Figure 3 where $x=r \cos \theta, y=r \sin$ $\theta$, and $z=z$ in the unwrapped form as shown in Fig. 4 . The stream velocity in the $x$ direction is represented by $u$.

$$
\text { Hence, } \quad u=u(x, y, z)
$$

Stream velocity in the y direction is represented by $v$.

$$
\text { Hence, } \quad v=v(x, y, z)
$$

and the stream velocity in the direction of $z$ is represented by w.

$$
\text { Hence, } \quad w=w(x, y, z)
$$

The equation of continuity was developed by writing a mass balance of the sterilized oil palm fruit stream over a volume element $\Delta x \Delta y \Delta z$ fixed in space within the digester screw press through which the stream was flowing (Fig. 3).

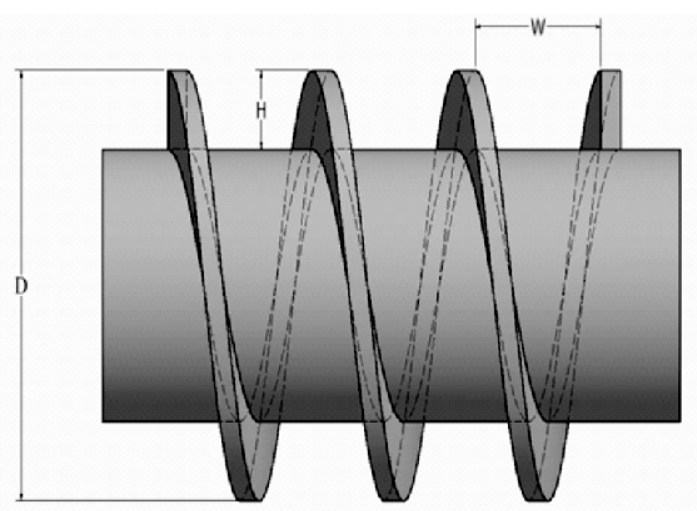

Fig. 2: Continuous helical flight on the shafts of the digester screw press. 


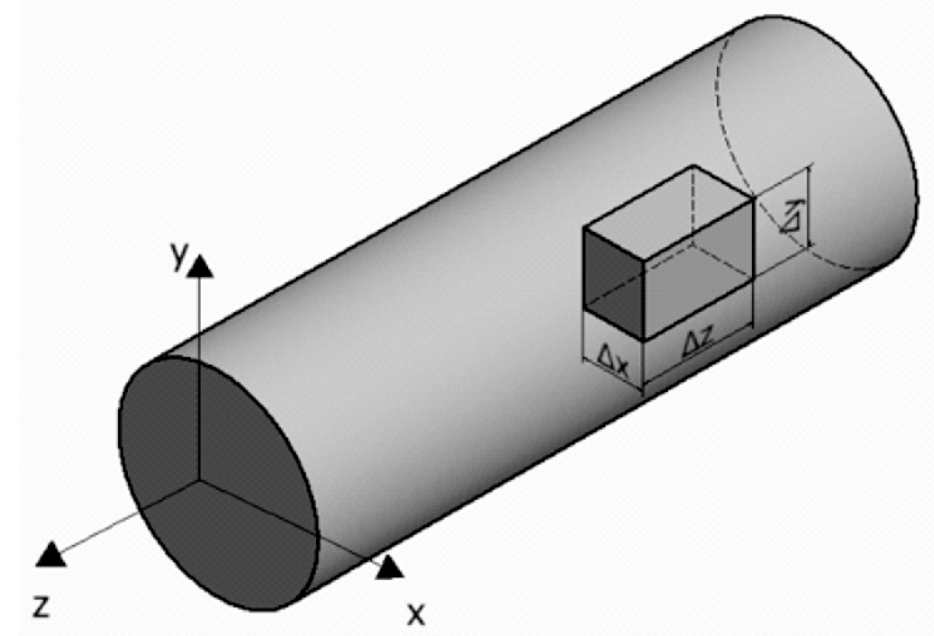

Figure 3: Stream element of volume $\Delta x \Delta y \Delta z$ flow through the circular geometries in the $x, y, z$ coordinate system. Source: Bird et al. (2006)

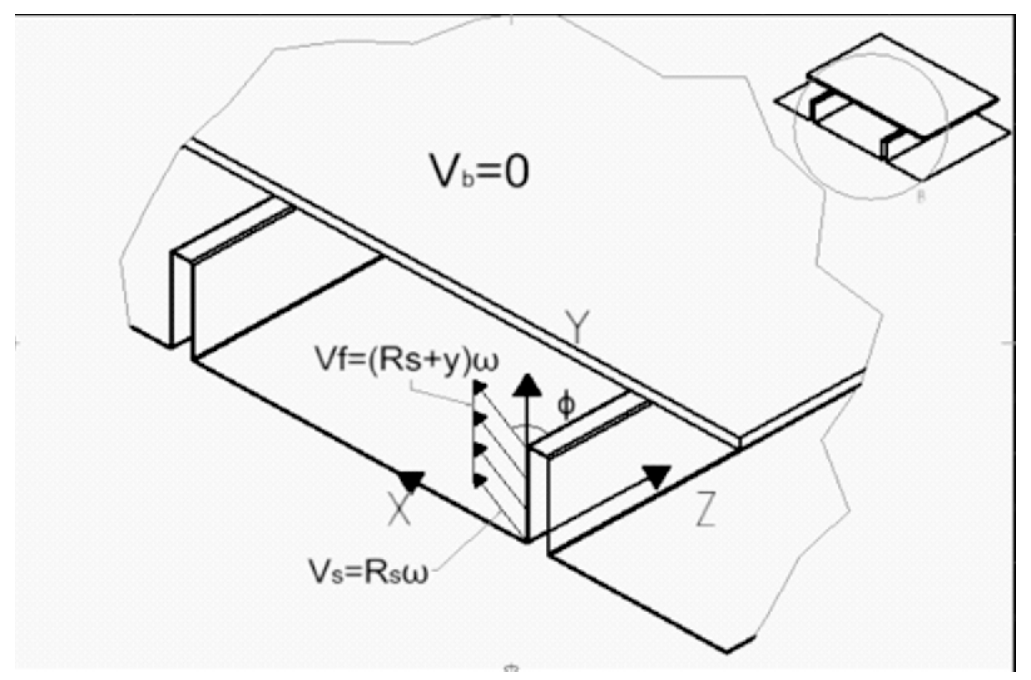

Fig. 4: Schematic representation of unwrapped pipe or cage and arms or screw (adapted from Li and Hsieh, 1996; Alves et al., 2009)

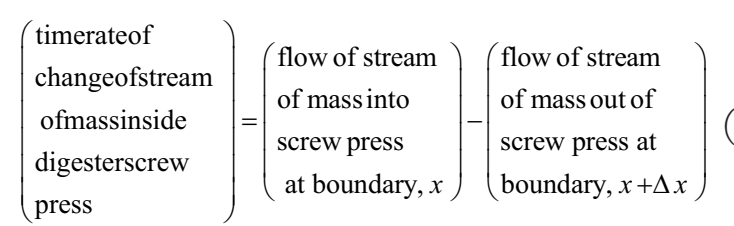

Adopting the equation of continuity (Bird et al. 2006) in the Cartesian $(x, y, z)$ coordinate to describe the flow of the sterilized oil palm fruit stream through the unwrapped pipe and cage of the digester screw press as:

$$
\frac{\partial \rho}{\partial t}+\frac{\partial(\rho u)}{\partial x}+\frac{\partial(\rho v)}{\partial y}+\frac{\partial(\rho w)}{\partial z}+\rho g=0
$$

where, $t=$ time of the stream flow, $\rho=$ density of sterilized oil palm fruit stream assumed to be a Newtonian fluid (Owolarafe et al. 2008).
To develop the equation of motion, the momentum balance over the volume element (Fig. 3) of the sterilized oil palm fruit stream is written in the following form (Bird et al., 2006):

$\left(\begin{array}{l}\text { rate of increase } \\ \text { of momentum } \\ \text { of stream }\end{array}\right)=\left(\begin{array}{l}\text { transfer of } \\ \text { momentum } \\ \text { in DSP at } x\end{array}\right)-\left(\begin{array}{l}\text { transfer of } \\ \text { momentum } \\ \text { in DSP at } x+\Delta x\end{array}\right)+\left(\begin{array}{l}\text { external } \\ \text { force on } \\ \text { stream }\end{array}\right)$ (6)

Assume the sterilized oil palm fruit stream is Newtonian, isothermal and incompressible fluid with constant density $(\rho)$ and viscosity $(\mu)$ and negligible body forces. (Owolarafe et al. 2008), then,

[Flow through digester $]=[$ Flow through transfer $]=[$ Flow through press $]$

The steady state equation of motion (Bird et al. 
2006) is given as:

$$
\rho \frac{D v}{D t}=-\nabla P+\mu \nabla^{2} v+\rho g
$$

It is assumed that the arms and screw curvatures are small and the curved surfaces of the channel can be unwrapped to become flat plates.

In Cartesian coordinates $x, y, z$ components of the equations of motion according to Bird et al. (2006) and Alves et al. (2009) are:

$x$-component: $\rho \frac{\partial u}{\partial t}+\rho\left[u \frac{\partial u}{\partial x}+v \frac{\partial u}{\partial y}+w \frac{\partial u}{\partial z}\right]=-\frac{\partial P}{\partial x}+\mu\left(\frac{\partial^{2} u}{\partial x^{2}}+\frac{\partial^{2} u}{\partial y^{2}}+\frac{\partial^{2} u}{\partial z^{2}}\right)$

$y$-component: $\rho \frac{\partial v}{\partial t}+\rho\left[u \frac{\partial v}{\partial x}+v \frac{\partial v}{\partial y}+w \frac{\partial v}{\partial z}\right]=-\frac{\partial P}{\partial y}+\mu\left(\frac{\partial^{2} v}{\partial x^{2}}+\frac{\partial^{2} v}{\partial y^{2}}+\frac{\partial^{2} v}{\partial z^{2}}\right)$

Z-component: $\rho \frac{\partial w}{\partial t}+\rho\left[u \frac{\partial w}{\partial x}+v \frac{\partial w}{\partial y}+w \frac{\partial w}{\partial z}\right]=-\frac{\partial P}{\partial z}+\mu\left(\frac{\partial^{2} w}{\partial x^{2}}+\frac{\partial^{2} w}{\partial y^{2}}+\frac{\partial^{2} w}{\partial z^{2}}\right)$

where $\mu=$ viscosity of the Newtonian fluid (mashed fruit stream).

Similar model by Li and Hsieh (1996) was solved analytically and single algebraic relationship for the down channel velocity and flow rate were obtained for intermediate as well as small and large values of the screw channel aspect ratio.

Using the simplified flow theory ( $\mathrm{Li}$ and Hsieh 1996) and for simplicity the arms and the screw are assumed to be small so that the pipe or cage surface and arms or screw channel can be unwrapped and become flat plates as shown in Fig. 4.

The following assumptions further simplify the problem of modelling flow:

(i) the flow is laminar, isothermal and fully developed

(ii) the sterilized oil palm fruit stream is Newtonian and incompressible

(iii) gravitational forces are negligible

(iv) there is no slip at the walls of pipe and cage of digester screw press (Owolarafe et al., 2008).

From these assumptions, equations (9), (10) and (11) are simplified to become (12), (13) and (14) respectively as follows:

$$
\frac{\partial P}{\partial x}=\mu \frac{\partial^{2} u}{\partial y^{2}}
$$

$\frac{\partial P}{\partial y}=0$

$\frac{\partial P}{\partial z}=\mu\left(\frac{\partial^{2} w}{\partial x^{2}}+\frac{\partial^{2} w}{\partial y^{2}}\right)$

where, $x, y, z$ are coordinates of channel width, channel depth and down channel respectively.

The appropriate boundary conditions are the following:

Drum or cage: $u(x, H)=0$

Arms or screw root: $u(x, 0)=R_{s} \Omega \cos \theta$

Arms or screw flight: $w(\mathrm{~W}, y)=(R s+y) \Omega \cos \theta(17)$

$$
\begin{aligned}
& w(0, y)=\left(R_{s}+y\right) \Omega \cos \theta \\
& w(0, H)=0 \\
& w(\mathrm{~W}, 0)=-\mathrm{Rs} \Omega \cos \phi
\end{aligned}
$$

Flow of sterilized oil palm fruit stream in the digester screw press is characterized into three stages, namely, flow through the digestion section in the $\mathrm{z}$ direction; flow through the transfer section in the $y$ direction and flow through the pressing section in the $\mathrm{z}$ direction with leakage through the holes of cage perforations in the $y$ direction.

\section{Isothermal flow of the digestion stage}

In the digestion section, the sterilized oil palm fruit stream flow (Figure 5) due to pressure P' imposed by stirring arms action is ultimately in the $z$ direction only, hence;

$u=0, v=0$

and using equations (12), (13), and (14) above. Since there is no leakage at all in the digester-pipe, 
$\frac{\partial u}{\partial y}=0$ and $\frac{\partial v}{\partial x}=0$

The model of flow of sterilized oil palm fruit stream motion in $x, y, z$ coordinate through the digester becomes:

$\frac{\partial P_{1}}{\partial x}=0$
$\frac{\partial P_{1}}{\partial y}=0$ $\frac{\partial P_{1}}{\partial z}=\mu\left(\frac{\partial^{2} w}{\partial x^{2}}+\frac{\partial^{2} w}{\partial y^{2}}\right)$

The following boundary conditions required to solve equations (25) for the down channel flow are:

Digester pipe: $w\left(x, H_{1}\right)=0$

Arms root: $w(x, 0)=R s \Omega \cos \phi$

Arms flights: $w(0, y)=(R s+y) \Omega \cos \phi$

$$
w\left(W_{1}, y\right)=(R s+y) \Omega \cos \phi
$$

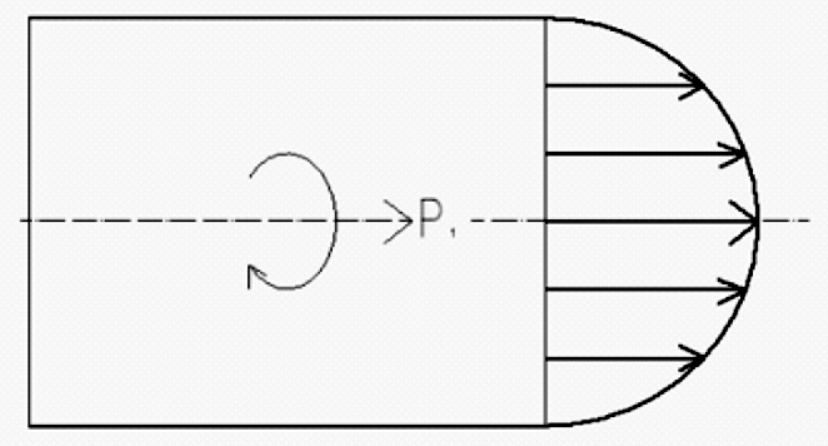

Fig. 5: Flow of stream of sterilized oil palm fruit

where,

$$
\begin{aligned}
& H_{1}=\text { Arms channel depth }(\mathrm{m}) \\
& \Omega=\text { Rotational speed of digester shaft }\left(\mathrm{s}^{-1}\right) . \\
& R s=\text { Arms root radius }(\mathrm{m})=\mathrm{R}_{\mathrm{b}}-\mathrm{H} . \\
& \theta=\text { Helix angle of arms }\left({ }^{(}\right) \text {. } \\
& W_{1}=\text { width of the channel at the interval } \\
& \text { radius of pipe }(\mathrm{m}) \text {. } \\
& \phi_{\mathrm{b}}=\text { Helix angle of arms at radius } \mathrm{R}_{\mathrm{b}}(9) . \\
& \mathrm{R}_{\mathrm{b}}=\text { internal radius of pipe }(\mathrm{m}) .
\end{aligned}
$$

\section{Isothermal flow in the transfer stage}

If the flow of the stream of oil palm fruit in the transfer section (Fig. 6) is due to pressure $P_{2}$ imposed by transfer arms action on down channel depth in the $y$ direction, hence $w=0, u=0$ and using overall model equations (9), (10) and (11) respectively, then

$$
\frac{\partial w}{\partial x}=0, \frac{\partial w}{\partial y}=0, \frac{\partial u}{\partial x}=0 \text { and } \frac{\partial u}{\partial y}=0
$$

Model of flow of sterilized oil palm fruit in $x, y, z$ coordinate through the transfer section becomes:

$$
\begin{aligned}
& \frac{\partial P_{2}}{\partial x}=0 \\
& \frac{\partial P_{2}}{\partial y}=0 \\
& \frac{\partial P_{2}}{\partial z}=0
\end{aligned}
$$

It is particularly interesting to note here that the flow pressure gradient of sterilized oil palm fruit stream in the transfer section is zero. In fact, the continuously flowing stream from the digester 


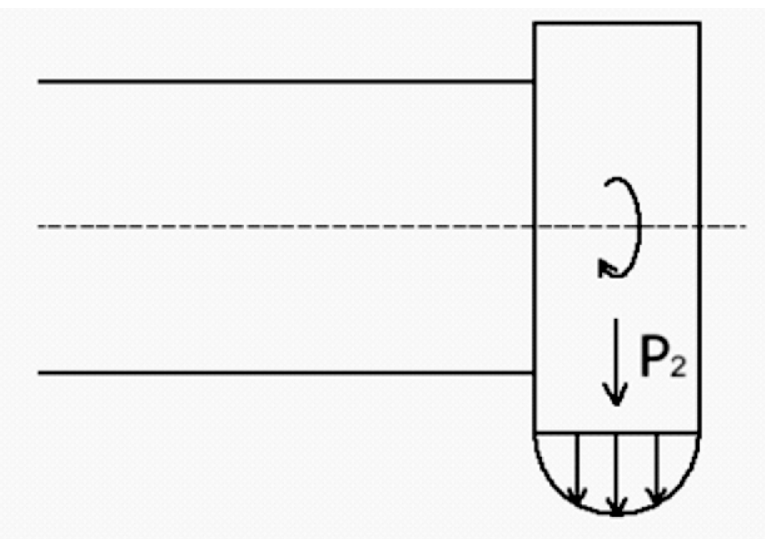

Fig. 6: Flow of oil palm fruit stream in the transfer section

in the $z$ direction is brought to an abrupt halt by the cover of the transfer pipe fixed vertically perpendicular to the direction of digestion stream flow. The transfer operation occur at a very short and negligible time, hence it is transient indeed.

\section{Isothermal flow in the pressing stage}

In the pressing section, nut fibre and crude palm oil mixture flow through the cage in a small section of the worm screw channel, i.e. space between the shaft surface and the internal wall of the cage. As the nut fibre crude palm oil mixture flows in $\mathrm{z}$ direction through the pressing section (Fig. 7), it is subjected to axial pressure $P_{3}$ exerted by the screw. The pressure causes flow of crude palm oil through the porous solid nut fibre matrix, leaks crude palm oil out in the $y$ direction through holes of cage perforations. palm fruit stream in the isothermal pressing section becomes:

$$
\frac{\partial P_{3}}{\partial x}=\mu \frac{\partial^{2} u}{\partial y^{2}}
$$

$$
\frac{\partial P_{3}}{\partial y}=0
$$

$$
\frac{\partial P_{3}}{\partial z}=\mu\left(\frac{\partial^{2} w}{\partial x^{2}}+\frac{\partial^{2} w}{\partial y^{2}}\right)
$$

The boundary conditions used in solving the above stated pressing down channel flow models are:

Screw root: $w(x, 0)=R_{s} \Omega_{b} \cos \Phi_{b}$

Screw flight: $w\left(O_{b}, y\right)=\left(R_{s b}+\mathrm{y}\right) \Omega_{b} \cos \Phi_{b}$

$$
w\left(W_{b}, y\right)=\left(R_{s b}+\mathrm{y}\right) \Omega_{b} \cos \Phi_{b}
$$

The model equations of motion of sterilized oil

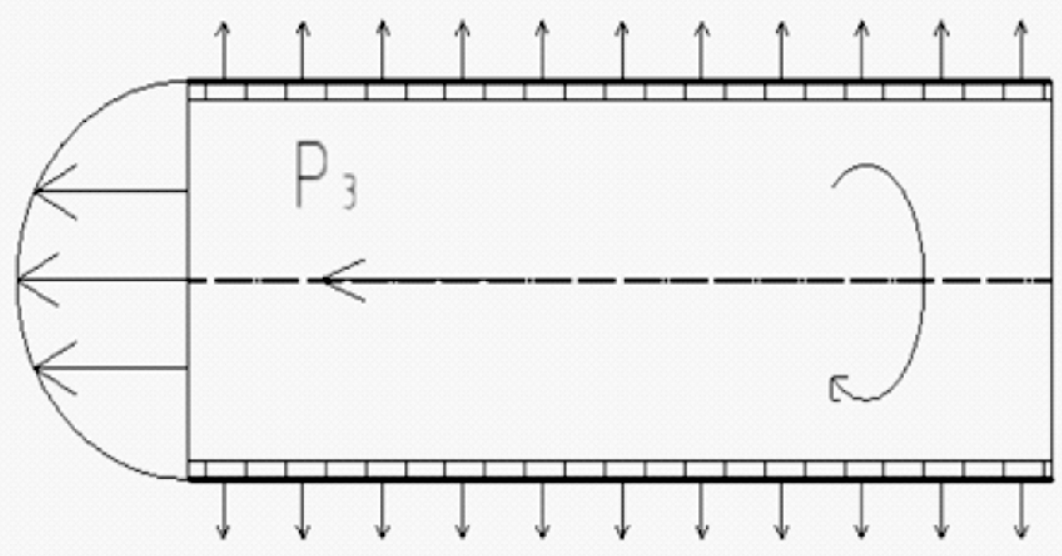

Fig. 7: Flow of the nut-fibre-crude palm oil mixture in $z$ direction through pressing section 
where: $\mathrm{H}_{\mathrm{b}}=$ screw channel depth (m)

$\Omega_{\mathrm{b}}=$ Rotational speed of the screw press $\operatorname{shaft}\left(\mathrm{s}^{-1}\right)$.

$\mathrm{R}_{\mathrm{sb}}=$ screw root radius $(\mathrm{m})=\mathrm{R}_{\mathrm{bb}}-\mathrm{H}_{\mathrm{b}}$

$\mathrm{W}_{\mathrm{b}}=$ width of channel at the interval radius of cage (m).

$\Phi_{\mathrm{b}}=$ Helix angle of screw at radius $\mathrm{R}_{\mathrm{bb}}\left({ }^{\circ}\right)$.

\section{Solutions to Models of Flow through Digester Screw Press}

The flow of the sterilized oil palm fruit stream through the digester had to be equal to the flow of the crude palm oil nut fibre mixture in the screw press under both isothermal and non-isothermal operations as indicated in momentum equations $(7,8)$ in line with the law of conservation of mass (or continuity equation) using the steady state assumption.

The models developed above were essentially boundary value problems which were solvable accordingly using different appropriate methods and boundary conditions. To be specific, the model equations of motion for the problem of isothermal flow of the sterilized oil palm fruit stream through the digester screw press in the partial differential equations without energy components were amenable to analytical solutions and hence were adopted.

Recall the simplified model equations [(12), (13) and (14)] of motion as follows:

$\frac{\partial P}{\partial x}=\mu \frac{\partial^{2} u}{\partial y^{2}}$

$\frac{\partial P}{\partial x}=0$

$\frac{\partial P}{\partial z}=\mu\left(\frac{\partial^{2} w}{\partial x^{2}}+\frac{\partial^{2} w}{\partial y^{2}}\right)$

The above equations can be found in the work of Li and Hsieh (1996), Tadmor and Gogos (1979). Existing solutions for equation (42) were based on boundary conditions provided by Badmus (2017) thus:

$w(x, H)=R_{b} \Omega \cos \theta$

$w(x, 0)=0$

$$
\begin{aligned}
& w(0, y)=0 \\
& w(W, y)=0
\end{aligned}
$$

This set of boundary conditions was valid for model of extruders with stationary screw and rotating barrel but not applicable for real extruders and digester screw press that always operate with rotating arms or screw and stationary barrel, drum or cage .

Experimental results (Alves et al. 2009; Choo et al. 1992) obtained using extruders with a rotating screw clearly showed the error predicted by this existing solution. The source of the error was elucidated by Li and Hsieh (1992) and another solution for drag flow in extruders with rotating screw and stationary barrel provided by the work of Li and Hsieh (1996).

In extruders with rotating screw and stationary barrel, the following boundary conditions were provided to solve equation (42) for the down channel flow:

Drum or cage: $w(x, H)=0$

Arms or screw root: $w(x, 0)=R_{s} \Omega \cos \phi(48)$

Arms or screw flight:

$$
\begin{aligned}
& w(0, y)=\left(R_{s}+y\right) \Omega \cos \phi(49) \\
& w(W, y)=\left(R_{s}+y\right) \Omega \cos \phi(50)
\end{aligned}
$$

Thus, different from the conventional parallel plate model, the arm/screw channel in this model was kept moving with actual velocity and the drum/cage surface was stationary. These boundary conditions (49) to (50) were defined based on the absolute velocities of the rotating screw.

Because equation (42) is a non-homogeneous second order partial differential with nonhomogeneous boundary conditions, it was separated into two parts with two sets of boundary conditions.

Rewriting equation (42) it becomes;

$\frac{\partial^{2} w}{\partial x^{2}}+\frac{\partial^{2} w}{\partial y^{2}}=\frac{1}{\mu} \frac{\partial P}{\partial z}$

Based on equation (41) and (42), it is known that the pressure gradient $\frac{\partial P}{\partial z}$ 
is either a constant or only a function of $z$. The unwrapped arms or screw and drum or cage systems, the coordinate defined earlier in this work , and the absolute velocities of the drum or cage, drum or screw root and arms or screw flights are shown in Fig. 4.

The actual boundary conditions for this problem are defined based on the following absolute velocities:

$$
\begin{array}{ll}
w(x, H)=f_{1}(x)= & 0,0 \leq x \leq W \\
w(x, 0)=f_{2}(x)=R_{s} \Omega \cos \theta & 0 \leq x \leq W
\end{array}
$$

$w(0, y)=g_{1}(y)=\left(R_{s}+y\right) \Omega \cos \theta \quad 0 \leq y \leq H(54)$ $w(W, y)=g_{2}(y)=\left(R_{s}+y\right) \Omega \cos \theta 0 \leq y \leq H(55)$

This is a non-homogeneous partial differential equation with non-homogeneous boundary conditions. This problem can be solved by separating it into two problems with homogeneous boundary conditions.

Assuming

$w(x, y)=w_{1}(x, y)+w_{2}(x, y)$

while separating the boundary conditions into two sets then the problem becomes:

$\frac{\partial^{2} w_{1}}{\partial x^{2}}+\frac{\partial^{2} w_{1}}{\partial y^{2}}=\frac{1}{\mu} \frac{\partial P}{\partial z}$

with the first set of boundary conditions:

$$
\begin{array}{lc}
w_{1}(x, H)=0, & 0 \leq x \leq W \\
w_{1}(x, 0)=R_{s} \Omega \cos \theta & 0 \leq x \leq W \\
w_{1}(0, y)=0 & 0 \leq y \leq H \\
w_{1}(W, y)=0 & 0 \leq y \leq H
\end{array}
$$

and

$\frac{\partial^{2} w_{2}}{\partial x^{2}}+\frac{\partial^{2} w_{2}}{\partial y^{2}}=\frac{1}{\mu} \frac{\partial P}{\partial z}$

with the second set of boundary conditions:

$$
\begin{array}{ll}
w_{2}(x, H)=0, & 0 \leq x \leq W \\
w_{2}(x, 0)=0 & 0 \leq x \leq W \\
w_{2}(0, y)=g_{1}(y) & 0 \leq y \leq H \\
w_{2}(W, y)=g_{2}(y) & 0 \leq y \leq H
\end{array}
$$

boundary conditions (58) to (61). The solution of $w_{1}(x, y)$ is written as:

$w_{1}(x, y)=\sum_{i=1}^{\infty} b_{i}(y) \sin (k x)$

In order to satisfy the boundary condition for $x=$ 0 and $x=W$, let $k=\frac{i \pi}{W}$ and define the following:

$b_{i}(y)=\frac{2}{W} \int_{0}^{W} w_{1}(x, y) \sin \left(\frac{i \pi}{W}\right) d x$

$\therefore \frac{2}{W} \int_{0}^{W} \frac{\partial^{2} w_{1}}{\partial x^{2}} \sin \left(\frac{i \pi x}{W}\right) d x=-\left(\frac{i \pi x}{W}\right)^{2} b_{i}(y)(69)$,

$\frac{2}{W} \int_{0}^{W} \frac{\partial^{2} w_{1}}{\partial y^{2}} \sin \left(\frac{i \pi}{W}\right) d x=\frac{\partial^{2}}{\partial y^{2}} b_{i}(y)$

and

$\frac{2}{W} \int_{0}^{W} \frac{\alpha}{\mu} \frac{\partial P}{\partial z} \sin \left(\frac{i \pi x}{W}\right) d x=\frac{a}{\mu} \frac{\partial P}{\partial z} \frac{2}{i \pi}[1-\cos i z]=\frac{a}{\mu} \frac{\partial P}{\partial z} \frac{4}{i \pi}$

For a non-zero solution, $i=1,3,5$. Therefore,

Now the homogeneous partial differential equation has been transformed into a homogeneous ordinary differential equation with the form:

$\frac{\partial^{2}}{\partial y^{2}} b_{i}(y)-\left(\frac{i \pi x}{W}\right)^{2} b_{i}(y)=\frac{a}{\mu} \frac{\partial P}{\partial z} \frac{4}{i \pi}$

The boundary condition becomes:

$b_{i}(0)=\frac{2}{W} \int_{0}^{W} w_{1}(x, 0) \sin \left(\frac{i \pi}{W}\right) d x=\frac{4 R_{s} \Omega \cos \theta}{i \pi}$

$b_{i}(H)=\frac{2}{W} \int_{0}^{W} w_{1}(x, H) \sin \left(\frac{i \pi x}{W}\right) d x=0$

Solving the above ordinary differential equation (72), the result is:

$b_{i}(y)=\frac{4 R_{s} \Omega \cos \theta}{i \pi} \frac{\sinh \frac{i \pi(H-y)}{W}}{\sinh \frac{i \pi H}{W}}+$

$\frac{a}{\mu} \frac{\partial P}{\partial z} \frac{4 W^{2}}{(i \pi)^{3}} \frac{\sinh \frac{i \pi(H-y)}{W}+\sinh \frac{i \pi y}{W}-1}{\sinh \frac{i \pi H}{W}}$

First, $w_{1}(x, y)$ is solved using the first set of 


$$
\begin{gathered}
w_{1}(x, y)= \\
\sum_{i=1,3,5}^{\infty}\left[\frac{4 R_{s} \Omega \cos \theta}{i \pi} \frac{\sinh \frac{i \pi(H-y)}{W}}{\sinh \frac{i \pi H}{W}}+\right. \\
\left.\frac{a}{\mu} \frac{\partial P}{\partial z} \frac{4 W^{2}}{(i \pi)^{3}} \frac{\sinh \frac{i \pi(H-y)}{W}+\sinh \frac{i \pi y}{W}-1}{\sinh \frac{i \pi H}{W}}\right] \sin \frac{i \pi x}{W}
\end{gathered}
$$

The method used for solving $w_{2}(x, y)$ is the same and the second set of boundary conditions were used.

The final solution for $w_{2}(x, y)$ is written as:

$$
\begin{gathered}
w_{2}(x, y)= \\
\sum_{i=1,3,5}^{\infty}\left(\frac{4 R_{s} \Omega \cos \theta}{i \pi}+\frac{b}{\mu} \frac{\partial P}{\partial z} \frac{4 W^{2}}{(i \pi)^{3}}+\right. \\
\left.\frac{\sinh \left(\frac{i \pi x}{H}\right)+\sinh \frac{i \pi(W-y)}{H}}{\sinh \frac{i \pi W}{H}}-\frac{b}{\mu} \frac{\partial P}{\partial z} \frac{4 W^{2}}{(i \pi)^{3}}\right) \sin \frac{i \pi y}{H}
\end{gathered}
$$

The volumetric flow rate for the overall drag flow is obtained by integrating the overall velocity distribution over the cross channel area of the arms or screw.

$$
\begin{aligned}
& Q=n_{t} \int_{0}^{W} \int_{0}^{H} w(x, y) d y d x= \\
& n_{1} \int_{0}^{W} \int_{0}^{H} w_{1}(x, y) d y d x+n_{2} \int_{0}^{W} \int_{0}^{H} w_{2}(x, y) d y d x
\end{aligned}
$$

Substituting the expression for $R_{s}$ and $W$ and rearranging the equation, the final result is presented as:

$$
\begin{aligned}
Q_{z}= & n_{t} R_{s} \Omega W^{2} \cos \theta\left[\frac{8}{\pi^{3}} \sum_{i=1,3,5, \ldots}^{\infty} \frac{1}{\pi^{3}}\left(\frac{e^{i t W W /(1)-}}{e^{i t / W /(+1)}}\right)\right] \\
& =n_{t}\left(R_{b}-H\right) \Omega\left(\frac{2 \pi R_{b} \theta}{n_{t}}-e\right)^{2} \cos ^{3} \theta
\end{aligned}
$$

For the cross channel flow velocity, $u$, equation (40) is rewritten as:

$$
\frac{\partial P}{\partial x}=\mu \frac{\partial^{2} u}{\partial y^{2}}
$$

First integration with respect to $y$ gives $\frac{\partial u}{\partial y}=\frac{1}{\mu} \frac{\partial P}{\partial x} y+c_{1}$

Second integration with respect to $y$ becomes

$u=\frac{1}{2 \mu} \frac{\partial P}{\partial x} y^{2}+c_{1} y+c_{2}$

The constant $c_{1}$ and $c_{2}$ are solved with the following boundary conditions:

$u(\mathrm{H})=0$

Then, the equation for $u$, becomes:

$u=\frac{1}{2 \mu} \frac{\partial P}{\partial x} y(y-H)-R s \Omega\left(1-\frac{y}{H}\right) \sin \theta$

In order to evaluate this pressure gradient, $u$ can be integrated over the channel depth $H$ as well as screw width $\mathrm{W}$, as:

$\iint_{00}^{H W} u d x d y=Q_{\text {leakage }}$

Substituting (85) for u in (86), we have

$\int_{00}^{H W}\left[\frac{1}{2 \mu} \frac{\partial P}{\partial x} y(y-H)-R s \Omega\left(1-\frac{y}{H}\right) \sin \theta\right] d x d y=Q_{\text {leakage }}(86)$

Evaluating (86) gives

$\frac{\partial P}{\partial x}=\frac{6 \mu}{H W^{2}(2 W-3 H)}\left[2 Q_{\text {leakage }}+W \Omega R_{s}(W-2 H) \sin \theta\right](87)$

This shows clearly that $\frac{\partial P}{\partial x}$ depends on arms or screw geometry, viscosity of the flowing stream, rotating speed of drum, clearance between the arms or screw tip and drum or cage respectively.

However, there is no leakage in digester hence

$\mathrm{Q}_{\text {leakage (digester) }}=0$

Therefore, pressure gradient in digester

$\frac{\partial P}{\partial x}=\frac{6 \mu \Omega R_{s}(W-2 H) \sin \theta}{H W(2 W-3 H)}$

In screw press, leakage of crude palm oil occurs through the perforated holes of the cage in the $y$ direction.

Then substituting equation (87) back into equation (84), the cross channel velocity, $u$ in the digester screw press becomes:

$u=\frac{3 y(y-H)}{H W^{2}(2 W-3 H)}\left[2 Q_{\text {leakage }}+\right.$

$\left.W \Omega R_{s}(W-2 H) \sin \theta\right]-R s \Omega\left(1-\frac{y}{H}\right) \sin \theta$ 
If the screw geometry of digester screw press is provided and the leakage flow $\mathrm{Q}_{\text {leakage }}$ of the crude palm oil through the perforated holes of the cage obtained from (80), then the velocity profile, $u$ can be determined.

Employing the tapered screw equation (Zhong 1991), we have

$Q=u \pi\left(R_{b}^{2}-R_{s}^{2}\right)-\frac{H W}{\sin \theta}$

Using Equation (92) in (91), the independent expressions for cross-channel velocity, $u$ of crude palm oil along the screw press axial axis $(y)$ is expressed as:

$u=\frac{1}{1-\frac{6 \pi y(y-H)\left(\mathrm{R}_{b}^{2}-\mathrm{R}_{s}^{2}\right)}{H W^{2}(2 W-3 H)}}$
$\left[\frac{3 y(y-H)}{H W(2 W-3 H)} \Omega R_{s}(W-2 H) \sin \theta\right.$

$$
\left.-R_{s} \Omega\left(1-\frac{y}{H}\right) \sin \theta-\frac{6 y(y-H)}{W(2 W-3 H) \sin \theta}\right]
$$

\section{Validation of mathematical models of the digester screw press.}

In this section, the model equation of velocity of the sterilized oil palm fruit stream was used to simulate velocity profile compared with actual velocity obtained experimentally. Also, the model equation of the volumetric flow rate of crude palm oil extract from the improved digester screw press was used in the simulation of extraction profile compared with experimentally determined volumetric flow rates of extracted crude palm oil.

\section{Results of velocity profile of digester screw press operations}

Simulations of velocity $(u)$ along the radial axis $(y)$ with respect to the final solution stated in Equation (92) of improved digester screw press operation over a range of channel height $(\mathrm{H})$ and screw width (W) for the digester, transfer and screw press sections gave the results shown here below. For Digester section, there is no leakage, hence $\mathrm{Q}_{\text {leakage }}=0$.

It is shown in Fig. 8, the result of velocity profile for digester arms ranges of values of between 0.05 $\mathrm{m}$ and $0.125 \mathrm{~m}$ for $=1090 \mathrm{~kg} / \mathrm{m}^{3} ;=\pi / 4 ; g=9.8$ $\mathrm{m} / \mathrm{s} ; \mu=86.97 ;=16.76 ; \mathrm{Rs}=0.035$;

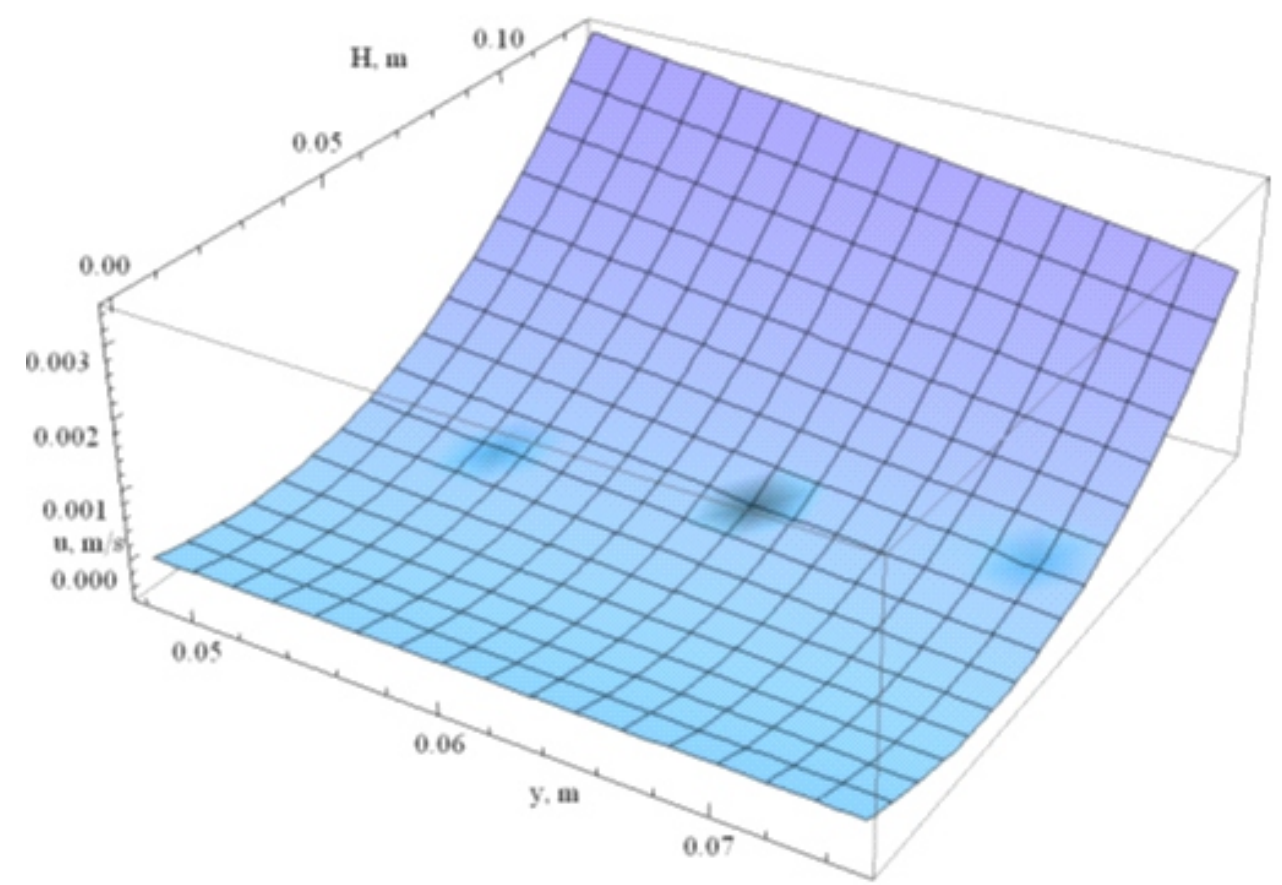

Fig. 8: Velocity Profile for digester arms ranges of values of $\mathrm{H}: 0.05 \leq \mathrm{H} \leq 0.125$ 
ymax $=0.0115$ which generate the data obtained for ten points on the velocity profile in Table 1. However, the velocity profile for the designed digester arm's length of $0.125 \mathrm{~m}$ is shown in Fig. 9.

The high velocity experienced with the flow stream at the centre could be attributed to the fact that the system behaves like an annulus where fluid layers close to the revolving digester arms assume the velocity of the arm while the velocity decrease as the distance of the fluid layers increases from the centre. The velocity of the stream at the wall of the cage almost assume the velocity of the stationary cage (Bird et al. 2006)

The results indicate the variation of oil palm fruit stream velocity with digester stirring arm's length at different radial distances within the cylindrical digester drum. The curvature of Fig. 8 is similar to that of Fig. 9. It could be observed that velocity increases at further radial distance from the centre of the digester drum while it decreases drastically towards shaft periphery at the middle of the cylindrical drum. This velocity profile result validates the designed digester arms length as $0.125 \mathrm{~m}$ while the actual velocity of the stream as shown on point 5 of Table 1 is $0.0102274 \mathrm{~ms}^{-1}$.

Similar to the digestion section, there is no leakage in Transfer section, hence $\mathrm{Q}_{\text {leakage }}=0$.

The velocity profile for ranges of transfer arm's length range of values between $0.05 \mathrm{~m}$ and 0.215 m; i.e. $0.05 \leqslant \mathrm{H} \leqslant 0.215$ for $=1090 \mathrm{~kg} / \mathrm{m}^{3}$ is shown in Fig. 9.

The velocity profile for the designed transfer arm's length of $0.125 \mathrm{~m}$ is shown in Fig. 10 while the data obtained for ten points on the velocity profile is displayed in Table 2 . This velocity profile result validates the designed transfer arm's length as $0.215 \mathrm{~m}$ while the actual velocity of the stream in the transfer section as shown on point 5 of Table 2 is $0.038345 \mathrm{~ms}^{-1}$.

Table 1: Profile of velocity u along digester radial axis (y)

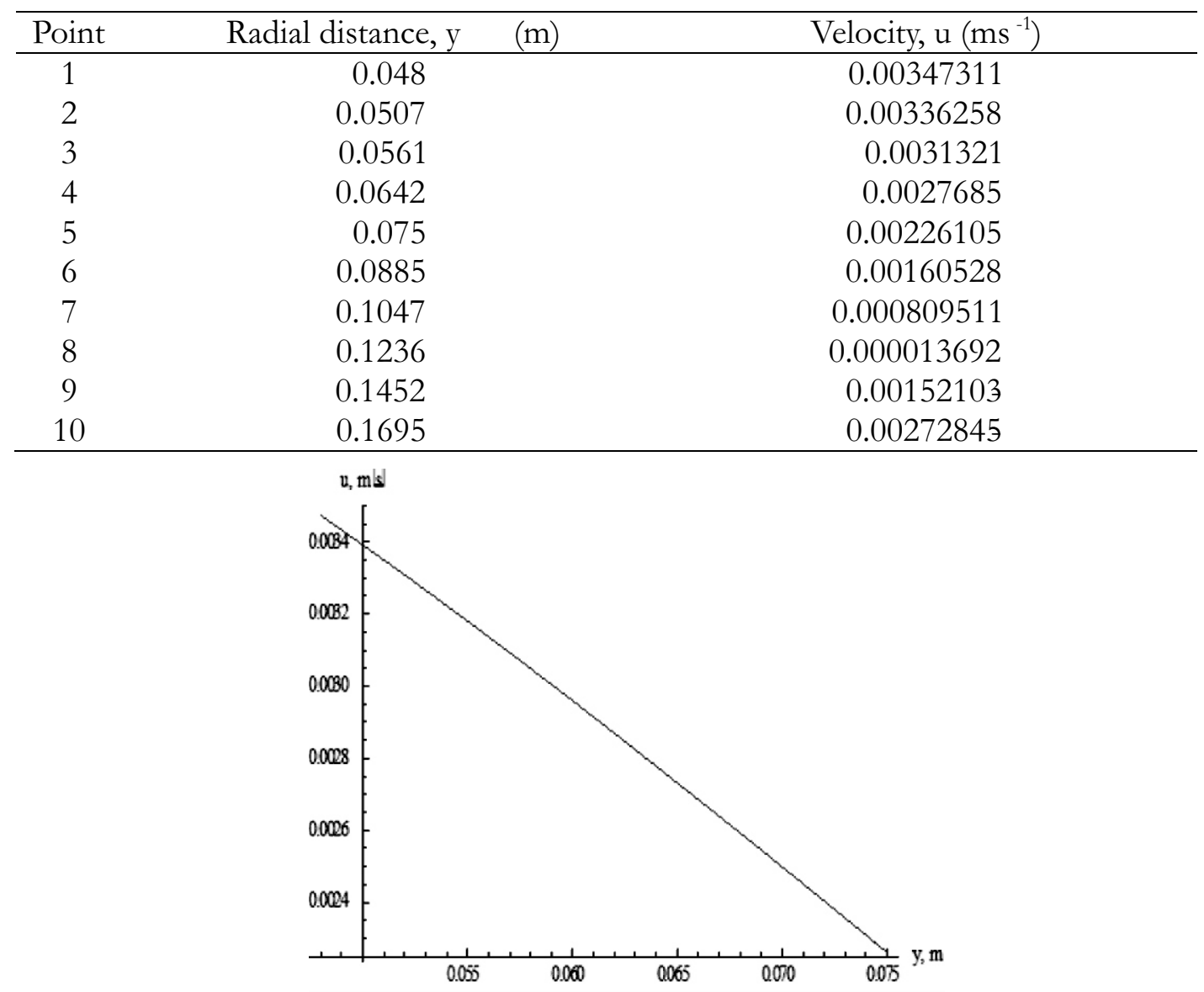

Fig. 9: Velocity profile for the designed Digester Arms, $H=0.125$ 


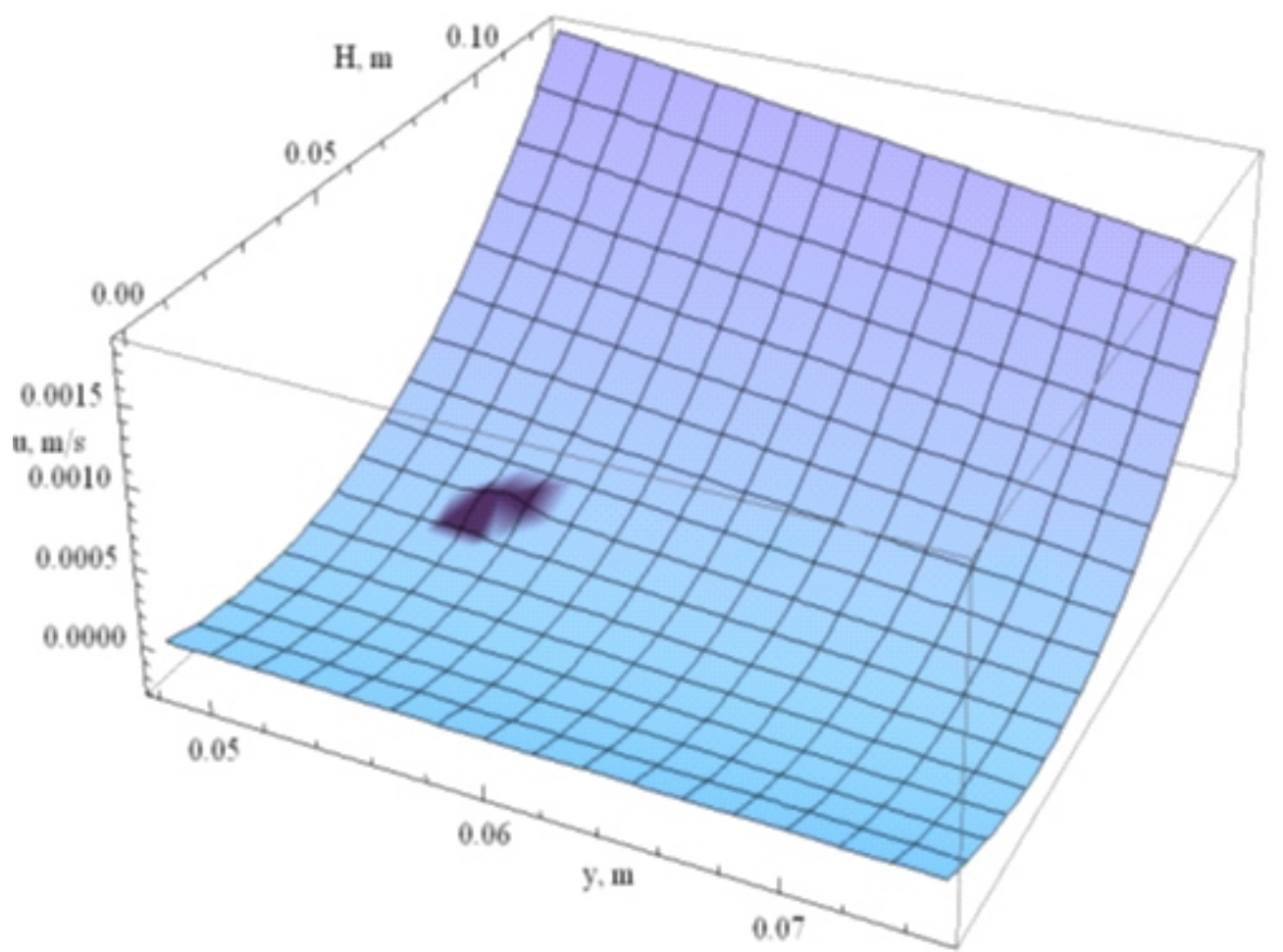

Fig. 10: Velocity Profile for ranges of Transfer Arms values of $\mathrm{H}: 0.05 \leq \mathrm{H} \leq 0.215$

Table 2: Profile of velocity u along the transfer radial axis (y)

\begin{tabular}{ccc}
\hline Point & Radial distance, $\mathrm{y}(\mathrm{m})$ & Velocity, $\mathrm{u}\left(\mathrm{ms}^{-1}\right)$ \\
1 & 0.048 & 0.00399423 \\
2 & 0.0507 & 0.00393579 \\
3 & 0.0561 & 0.00380694 \\
4 & 0.0642 & 0.00359041 \\
5 & 0.075 & 0.00327109 \\
6 & 0.0885 & 0.00283951 \\
7 & 0.1047 & 0.00229201 \\
8 & 0.1236 & 0.00163014 \\
9 & 0.1452 & 0.000864489 \\
10 & 0.1695 & 0.0000808323 \\
\hline
\end{tabular}

Effect of screw flight on velocity of stream in the digester screw press operation

As shown in Figs 11, 12 and 13 and Table 3, the velocity of stream decreased rapidly from $0.0100763 \mathrm{~ms}^{-1}$ when screw flight was $0.025 \mathrm{~m}$ until actual inner surface of the perforated cage where screw flight had increased to $0.05 \mathrm{~m}$ when the velocity of stream became $0.000886712 \mathrm{~ms}^{-1}$. It is important to note that screw flight would not exceed $0.05 \mathrm{~m}$ when the screw shaft diameter is $0.05 \mathrm{~m}$ for the $0.15 \mathrm{~m}$ inner diameter of screw press perforated cage. But a shaft-less screw with flight of $0.075 \mathrm{~m}$ increase stream velocity to $0.032288 \mathrm{~ms}^{-1}$. Similar results were obtained by $\mathrm{Li}$ and Hsieh (1996) on modelling of flow through an extruder. Velocity of flow was observed to vary with screw flight and channel depth. Velocity of flow was also observed to vary with screw length which is a function of screw flight by Jain and Jain (2015).

\section{Simulation of volumetric flow rate of crude palm oil extract of the improved digester screw press operations}

The crude palm oil extraction volumetric flow rate, $\mathrm{Q}_{\text {leakage }}$ along the radial axis (y) over a range of channel height $(\mathrm{H})$ for the screw press sections obtained the results is derived by employing Eq. (92) in Eq. (91) as 


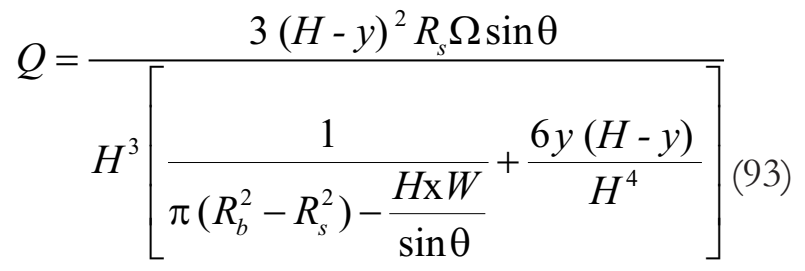

Applying model Eq. (93) for $=1090 \mathrm{~kg} / \mathrm{m}^{3}$; = $\pi / 4 ; g=9.8 \mathrm{~m} / \mathrm{s} ; \mu=86.97 ;=16.76$; Rs =0.035; The crude palm oil extraction volumetric flow rate (Qleakage) profile is shown in Fig. 14 for the helical worm screw channel height $(\mathrm{H})$ values within the range $0 \leq \mathrm{H} \leq 0.05 \mathrm{~m}$. The profile of

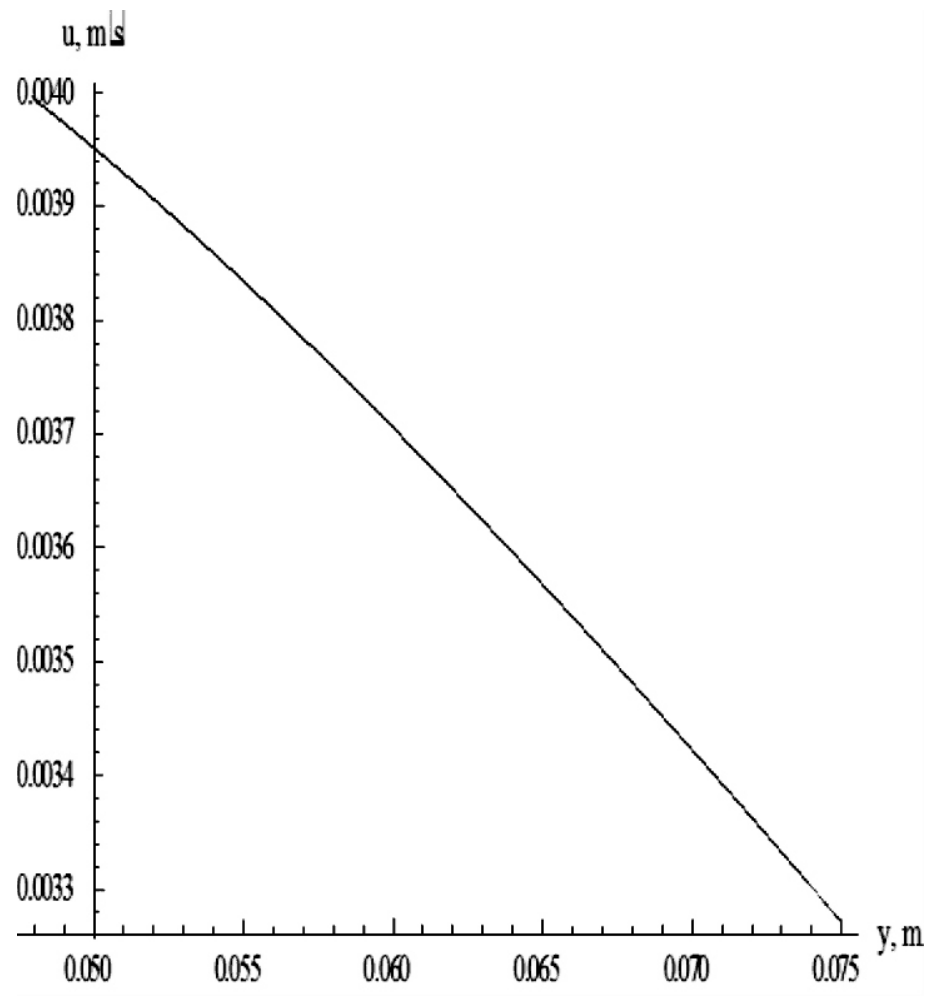

Fig. 11: Velocity profile for the designed Transfer Arms, $H=0.215$

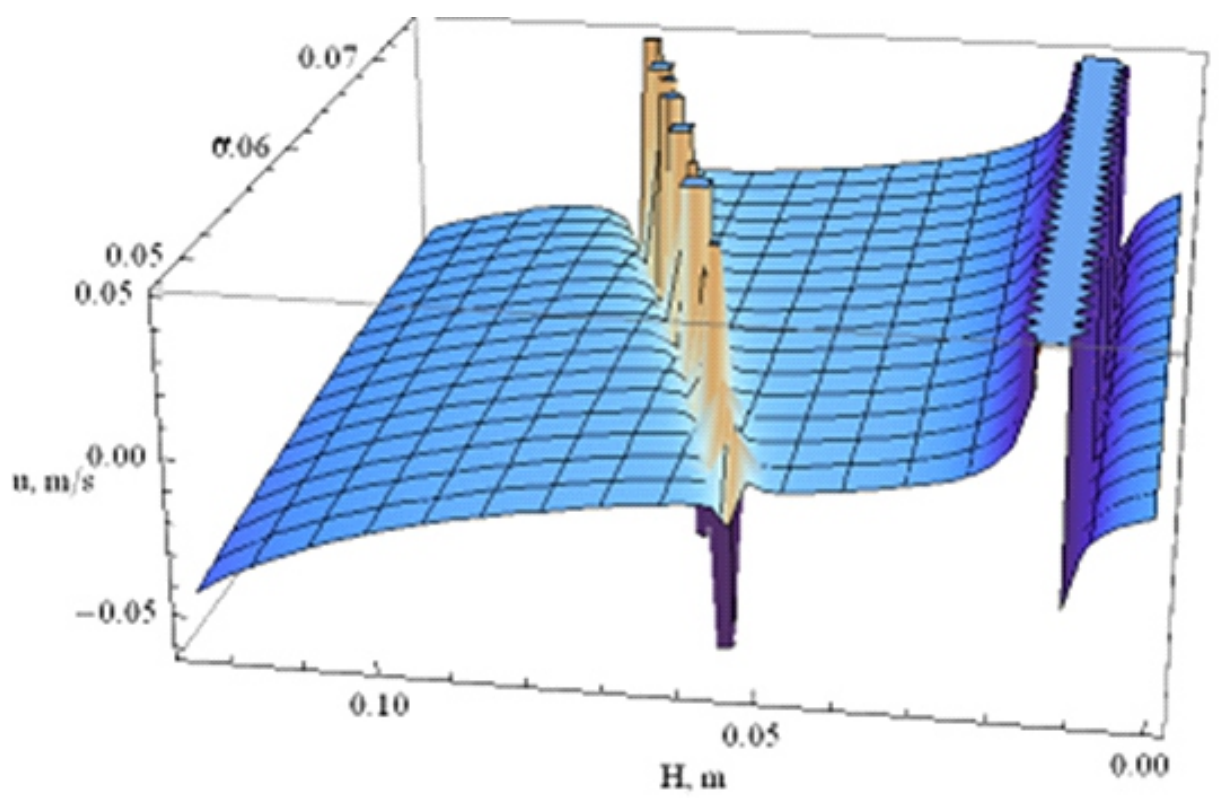

Fig. 12: Velocity profile for screw press ranges of values of $\mathrm{H}: 0 \leq \mathrm{H} \leq 0.15$ 
Badmus et al.: Mathematical Modelling of Digester-Screw Press Process

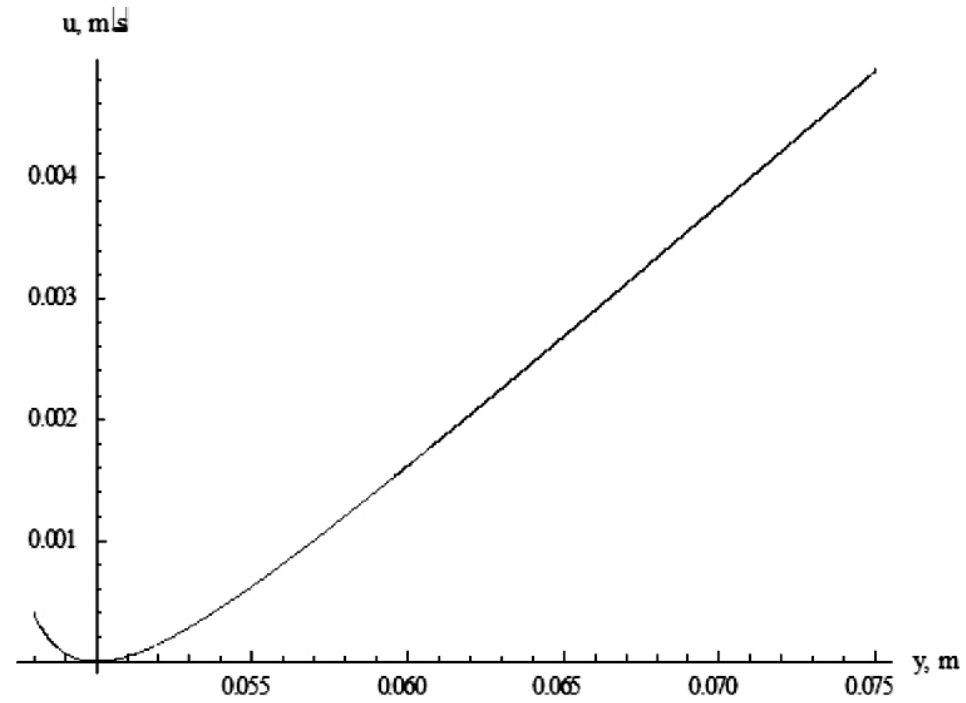

Fig. 13: Velocity profile for the designed Screw worm, $\mathrm{H}=0.05$

Table 3: Profile of velocity u along the screw worm radial axis (y)

\begin{tabular}{ccc}
\hline Point & Radial distance, $\mathrm{y}(\mathrm{m})$ & Velocity, $\mathrm{u}\left(\mathrm{ms}^{-1}\right)$ \\
1 & 0.048 & 0.000395293 \\
2 & 0.0507 & 0.0000226918 \\
3 & 0.0561 & 0.000829821 \\
4 & 0.0642 & 0.00251205 \\
5 & 0.075 & 0.00487483 \\
6 & 0.0885 & 0.00784876 \\
7 & 0.1047 & 0.0114086 \\
8 & 0.1236 & 0.0155456 \\
9 & 0.1452 & 0.0202576 \\
\hline
\end{tabular}

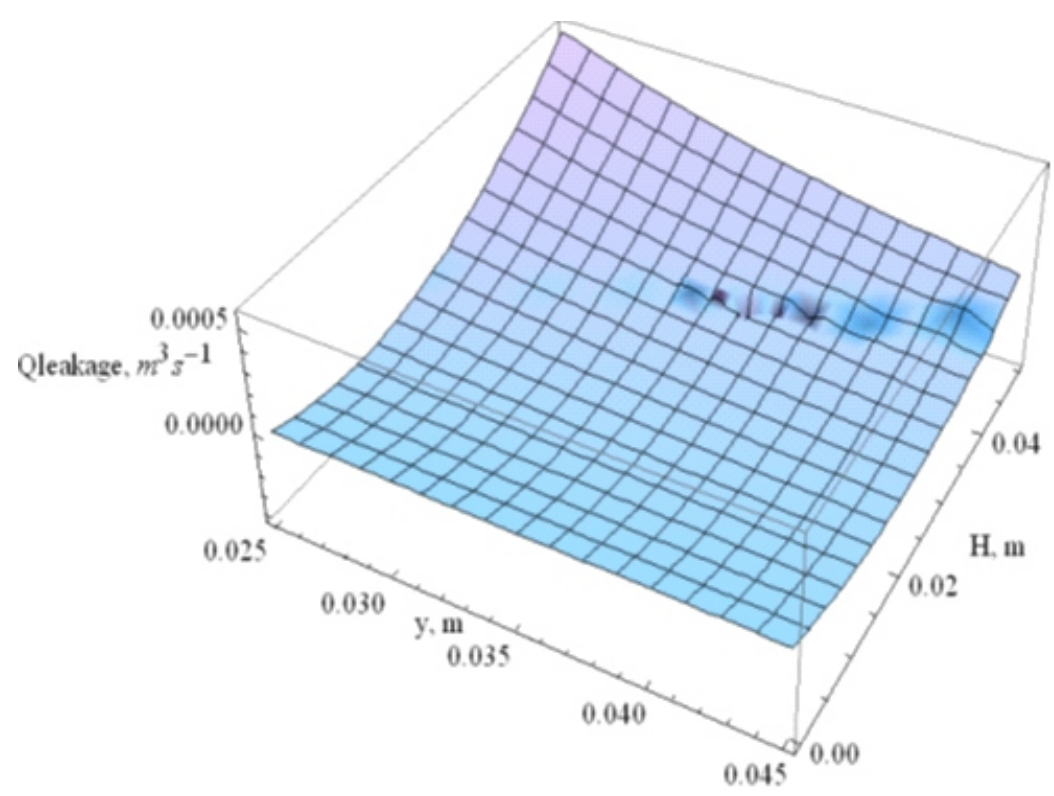

Fig. 14: Volumetric flow profile of crude palm oil extracted by digester screw press for ranges of values of $\mathrm{H}: 0 \leq \mathrm{H} \leq 0.05$ 
volumetric flow rate of crude palm oil (Qleakage) extract of digester screw press for designed screw worm shaft radius $\mathrm{Rs}=0.035 \mathrm{~mm}$ and value of channel height $\mathrm{H}=0.05$ is shown in Fig. 15. Data obtained for ten points on the crude palm oil extraction volumetric flow rate Qleakage profile is shown in Table 4. The trend of the results observed from Figs 14 and 15, and Table 4 could be attributed to the fact that the pressure exerted on the mash is high at the centre and decreases along the radius of the barrel. The higher the pressure exerted on the mash the higher the volumetric flow of the fluid. Thus the volumetric flow rate decreases as the distance from the centre decreases. This result is in agreement with the findings of Owolarafe et al. (2008) on hydraulic expression of crude palm oil and that of Craft and Hawkins (1991) on flow of oil in oil reservoir.
Comparison of volumetric flow rates measured and predicted by the model simulated profile of crude palm oil extracted by digester screw press values at $\mathrm{H}=0.05 \mathrm{~m}$

Table 5 shows the measured volumetric flow rates and corresponding extraction efficiencies for digester screw press' operational speeds at $10 \mathrm{rpm}$, $15 \mathrm{rpm}$ and $20 \mathrm{rpm}$. Table 6 shows a comparison of experimentally measured and predicted values of the volumetric flow rates of crude palm oil extracted by the improved digester screw press integration oil palm fruit transfer and spring choke mechanism at $50 \mathrm{~mm}$ channel height and screw flight irrespective of the screw length. The measured values compared favourably with the model equation predicted values especially when the volumetric flow rates of crude palm oil extracted by the machine measured $5.7 \times 10^{-6} \mathrm{~m}^{3} \mathrm{~s}^{-1}$ and $4.6 \times 10^{-6} \mathrm{~m}^{3} \mathrm{~s}^{-1}$ where the predicted values really coincide with actual measured values of crude palm oil volumetric flow rates,

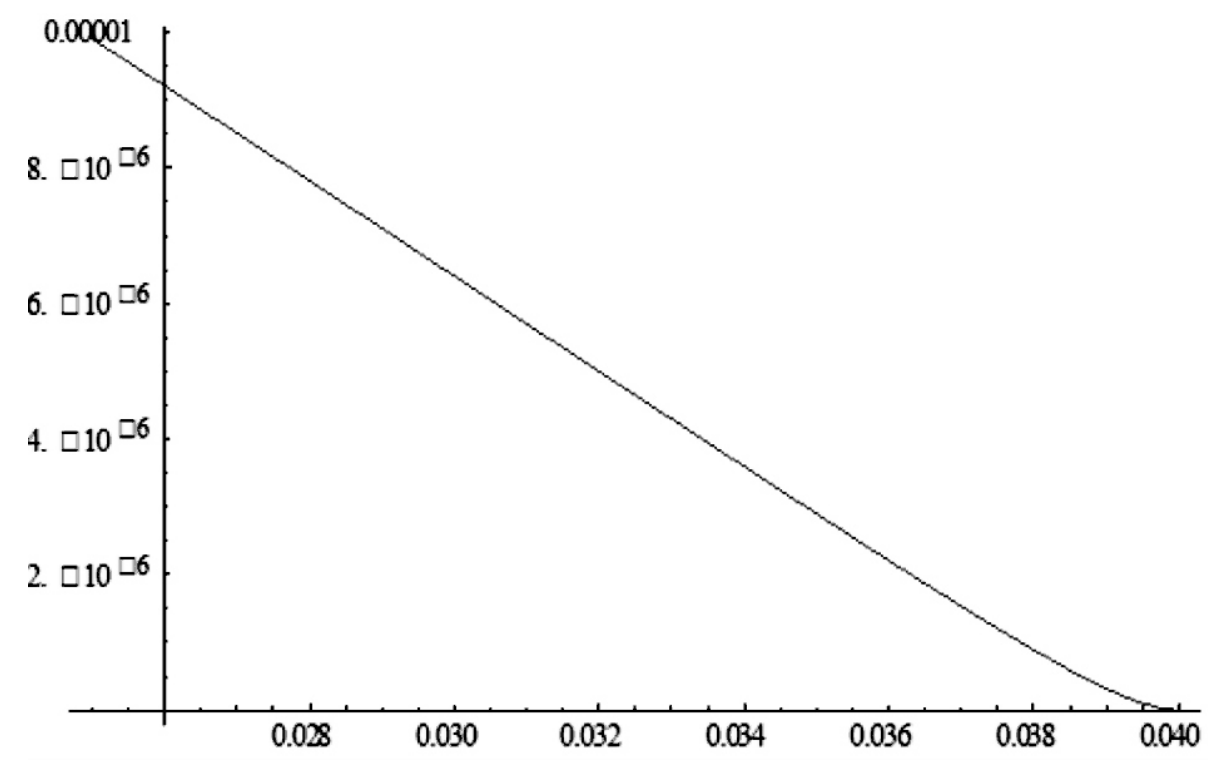

Fig. 15: Profile of volumetric flow rate of crude palm oil (Qleakage) extract of digester screw press for designed screw worm shaft radius Rs $=0.035 \mathrm{~m}$ and value of channel height $\mathrm{H}=0.04$ 
Table 4: Profile of volumetric flow of crude palm oil $\mathrm{Q}_{\text {leakage }}$ extract of digester screw press along the press cage radial axis (y)

\begin{tabular}{ccc}
\hline Point & Radial distance, $\mathrm{y}(\mathrm{m})$ & Qleakage $\left(\mathrm{m}^{3} \mathrm{~s}^{-1}\right)$ \\
\hline 1 & 0.025 & 0.000563091 \\
2 & 0.027 & 0.000479171 \\
3 & 0.029 & 0.00040603 \\
4 & 0.031 & 0.000341742 \\
5 & 0.033 & 0.000284821 \\
6 & 0.035 & 0.000234112 \\
7 & 0.037 & 0.000188705 \\
8 & 0.039 & 0.000147891 \\
9 & 0.041 & 0.000111134 \\
10 & 0.043 & 0.0000780724 \\
\hline
\end{tabular}

Table 5: Measured volumetric flow rates and corresponding extraction efficiencies for digester screw press' operational speeds at $10 \mathrm{rpm}, 15 \mathrm{rpm}$ and $20 \mathrm{rpm}$

\begin{tabular}{cccccc}
\hline $\begin{array}{c}\text { Volumetric } \\
\text { flow rate, } \\
\left(\mathrm{m}^{3} \mathrm{~s}^{-1}\right)\end{array}$ & $\begin{array}{c}\text { Extraction } \\
\text { efficiency at } \\
10 \mathrm{rpm}\end{array}$ & $\begin{array}{c}\text { Volumetric } \\
\text { flow rate, } \\
\left(\mathrm{m}^{3} \mathrm{~s}^{-1}\right)\end{array}$ & $\begin{array}{c}\text { Extraction } \\
\text { efficiency } \\
\text { at } 15 \mathrm{rpm}\end{array}$ & $\begin{array}{c}\text { Volumetric } \\
\text { flow rate, } \\
\left(\mathrm{m}^{3} \mathrm{~s}^{-1}\right)\end{array}$ & $\begin{array}{l}\text { Extraction } \\
\text { efficiency at 20 } \\
\text { rpm }\end{array}$ \\
\hline $4.3 \times 10^{-6}$ & $92 \%$ & $5.7 \times 10^{-6}$ & $73 \%$ & $6.9 \times 10^{-6}$ & $70 \%$ \\
$4.2 \times 10^{-6}$ & $89 \%$ & $5.5 \times 10^{-6}$ & $70 \%$ & $6.5 \times 10^{-6}$ & $66 \%$ \\
$4.0 \times 10^{-6}$ & $80 \%$ & $5.1 \times 10^{-6}$ & $65 \%$ & $5.8 \times 10^{-6}$ & $60 \%$ \\
$3.8 \times 10^{-6}$ & $70 \%$ & $5.7 \times 10^{-6}$ & $71 \%$ & $6.5 \times 10^{-6}$ & $66 \%$ \\
$3.6 \times 10^{-6}$ & $67 \%$ & $5.5 \times 10^{-6}$ & $69 \%$ & $6.4 \times 10^{-6}$ & $65 \%$ \\
$3.4 \times 10^{-6}$ & $67 \%$ & $5.1 \times 10^{-6}$ & $65 \%$ & $6.1 \times 10^{-6}$ & $62 \%$ \\
$3.5 \times 10^{-6}$ & $65 \%$ & $5.5 \times 10^{-6}$ & $70 \%$ & $6.2 \times 10^{-6}$ & $63 \%$ \\
$3.2 \times 10^{-6}$ & $63 \%$ & $5.3 \times 10^{-6}$ & $65 \%$ & $6.1 \times 10^{-6}$ & $62 \%$ \\
$3.0 \times 10^{-6}$ & $60 \%$ & $5.0 \times 10^{-6}$ & $64 \%$ & $5.8 \times 10^{-6}$ & $60 \%$ \\
\hline
\end{tabular}

Table 6: Comparison of volumetric flow rates measured and predicted by the model simulated profile of crude palm oil extracted by digester screw press values at $\mathrm{H}=0.05 \mathrm{~m}$

\begin{tabular}{ccc}
\hline Points & Predicted volumetric flow rates $\left(\mathrm{m}^{3} \mathrm{~s}^{-1}\right)$ & Measured volumetric flow rates $\left(\mathrm{m}^{3} \mathrm{~s}^{-1}\right)$ \\
\hline 1 & $9.90533 \times 10^{-6}$ & $6.9 \times 10^{-6}$ \\
2 & $8.86254 \times 10^{-6}$ & $6.5 \times 10^{-6}$ \\
3 & $7.81336 \times 10^{-6}$ & $5.8 \times 10^{-6}$ \\
4 & $5.70322 \times 10^{-6}$ & $5.7 \times 10^{-6}$ \\
5 & $4.64669 \times 10^{-6}$ & $4.6 \times 10^{-6}$ \\
6 & $3.59374 \times 10^{-6}$ & $3.6 \times 10^{-6}$ \\
7 & $2.55122 \times 10^{-6}$ & $2.4 \times 10^{-6}$ \\
\hline
\end{tabular}




\section{CONCLUSION}

The mathematical model equations of the flow of the sterilized oil palm fruit stream through pipes of the digester screw press integration oil palm fruit transfer and spring choke mechanism under isothermal operations were developed and solved

Results of volumetric flow rate predictions by the mathematical model equations have shown to be very close to the actual experimentally measured crude palm oil volumetric flow rates at $10 \mathrm{rpm}, 15$ $\mathrm{rpm}$ and $20 \mathrm{rpm}$ speeds of screw press operation while optimum extraction efficiency of the machine is $92 \%$ at 3.5 worms' length of the screw and $0.05 \mathrm{~m}$ screw flight. In general, the models developed and the data presented in the study will be useful in optimising oil palm fruit processing operations and design and development of the digester screw press.

\section{Acknowledgement}

The authors wish to acknowledge the support provided by the Nigerian Institute for Oil palm Research, (NIFOR), Benin City, Nigeria in providing the materials for the research.

\section{REFERENCES}

Alves, M. V. C, Barbosa, J. R. Jr, Prata, A. T. 2009: Analytical solution of single screw extrusion applicable to intermediate values of screw channel aspect ratio. Journal of Food Engineering, 92 152-156

Babatunde, O. O. 1987. Sterilization and mechanical digestion of oil palm fruits (Elaeis guinnensis jacqin). A thesis submitted in partial fulfilment of the requirements for the award of a doctor of philosophy degree in Agricultural Engineering at the University of

Badmus, G. A. 2018. Modelling of an improved digester screw press for expression of oil from oil palm fruit. An unpublished $\mathrm{PhD}$ thesis of the Department of Agricultural and Environmental Engineering, Obafemi Awolowo University, Ile-Ife, Nigeria.

Badmus, G. A. 1993. NIFOR automated small scale oil palm fruit processing equipmentits need, development and cost effectiveness-In Proc. 1991 Int. Oil Palm
Conf-Chemistry \&

Bird, R. B., Stewart, W. E., Lightfoot, E. N. 2006. Transport Phenomena. Wiley-India Edition.

Choo, K. P., Neelakantan, N. R. and Pitman, J. F. T. 1980. Experimental deep-channel velocity profiles and operating characteristic for a single-screw extruder. Polymer Engineering and science 20,349-356.

Craft, B. C. and Hawkins, M. F. 1991. Applied Petroleum Reservoir Engineering (second ed.). Prentice Hall PTR Prentice Hall Inc. pp 230-237.

Jain, D. and Jain, S. 2015. Performance evaluation of screw-press oil expeller using a continuous spiral and decreasing length of pitch of screw. Agricultural Engineering International, CIGR Journal, 17 (1), 213 222.

Li, Y. and Hsieh, F. 1996. Modelling of flow in a single screw extruder. Journal of food Engineering 17,353-375.

Omoti, U. 2011. The Nigeria oil palm industry: Past performances and event challenges. Invited paper presented at the workshop on Tapping into Opportunities in the Oil Palm Sector of Nigeria's Economy organised by FCMB plc Benin City, Nigeria; 24-25 $5^{\text {th }}$ October, pp1-36. (Unpublished).

Owolarafe, O. K. 2015. "Building a Paradise in Nigeria-The R \& D Option for Small and Medium Scale Agro-Allied Industries", the $282^{\text {nd }}$ Inaugural Lecture Series of Obafemi Awolowo University, Ile-Ife, Nigeria presented on $22^{\text {nd }}$ December, 2015, Obafemi Awolowo University Press Ltd.

Owolarafe, O. K. and Faborode,. M. O. 2008. Micro-structural Characterisation of Palm Fruit at Stages of Sterilisation and Digestion in Relation to Oil Expression. Journal of Food Engineering, UK, vol. 85, issue 4, 598-605.

Owolarafe, O. K., Osunleke, A. S., Odejobi, O. A., Ajadi, S. O. and Faborode, M. O. 2008. Mathematical Modelling and Simulation of Hydraulic Expression of Oil from Oil Palm Fruit, Biosystems Engineering, UK, Vol. 101, 331-340 
Owolarafe, O. K. and Oni, O. A. 2011 Modern mill technology and centralised processing system, an alternative for improving performance of palm oil mills in Abia State, Nigeria- Technology in Society, 33 12-22 Elsevier UK

Tadmor, Z. and Gogos, C. G. 1979. Principles of Polymer Processing; John Wiley, NY.
Zhong, Z. 1991. Theoretical and Experimental Analysis of the Compaction Process in a Tapered Screw press. A thesis submitted in fulfilment of the requirement of the degree of Doctor of Philosophy in Agricultural Engineering. The University of Newcastle Upon Tyne. (Unpublished). 